\title{
Modulating effect of cardiac rehabilitation on autonomic nervous system function in patients with coronary artery disease
}

\author{
Pedro RIO ${ }^{1}$, MD; Tiago PEREIRA-DA-SILVA ${ }^{1}, \mathrm{MD}$; Ana ABREU ${ }^{1}, \mathrm{MD}$; Custódia FILIPE ${ }^{2}, \mathrm{MD}$; \\ Rui SOARES ${ }^{1}$, MD; Guilherme PORTUGAL ${ }^{1}$, MD; Teresa ALVES ${ }^{1}, \mathrm{CT}^{*}$; Sofia SILVA ${ }^{1}, \mathrm{CT}^{*}$; \\ Isabel MIMOSO${ }^{2}$, MD; Rui CRUZ FERREIRA ${ }^{1}, \mathrm{MD}$
}

${ }^{1}$ Department of Cardiology, Hospital de Santa Marta, Centro Hospitalar de Lisboa Central. Lisbon, Portugal; ${ }^{2}$ Department of Physical Medicine and Rehabilitation, Hospital de Santa Marta, Centro Hospitalar de Lisboa Central. Lisbon, Portugal.

*cardiovascular technician

Introduction Autonomic nervous system (ANS) dysfunction is associated with prognosis in coronary artery disease (CAD). We aimed to study the cardiac rehabilitation (CR) modulating effect on autonomic function, through heart rate variability (HRV) and heart rate recovery (HRR) after exercise, in CAD patients and the associated factors.

Methods This study is a retrospective analysis of CAD patients in sinus rhythm who complete a single-centre CR programme and complementary evaluation including HRV study, cardiopulmonary exercise testing, echocardiogram.

Results Our sample included 142 CAD patients ( $85.9 \%$ male, $57.8 \pm 10.2$ years, $85 \%$ post-acute coronary syndrome, $15 \%$ stable CAD). There was a significant improvement in SDNN $(120.7 \pm 40.7 \mathrm{~ms}$ vs $127.6 \pm 41.5 \mathrm{~ms} ; P=0.019)$, resting HR $\left(71.3 \pm 10.7 \mathrm{~min}^{-1}\right.$ vs $\left.69.0 \pm 10.9 \mathrm{~min}^{-1} ; P=0.015\right)$ and HRR $\left(23.8 \pm 12.3 \mathrm{~min}^{-1}\right.$ vs $\left.27.1 \pm 12.5 \mathrm{~min}^{-1} ; P=0.017\right)$ following CR. Lower erythrocyte sedimentation rate (OR $0.911 ; 95 \%$ confidence interval (CI) $0.838-0.989$, $P=0.027$ ), normal left ventricular (LV) function/mild LV systolic dysfunction (OR 7.879; $95 \% \mathrm{Cl} 2.753-17.351, P=0.009)$ and SDNN lower than $100 \mathrm{~ms}$ (OR 9.325;95\% Cl 1.775-48.978, $P=0.008)$ were independently associated with SDNN improvement; quit smoking (OR 4.323; 95\% Cl 1.136-16.454, $P=0.014)$ and abnormal HRR (OR $8.023 ; 95 \% \mathrm{Cl} 1.049-64.811, P=0.035$ ) were independently associated with HRR improvement.

Conclusion The cardiac rehabilitation programme induced a positive modulation of the autonomic function in CAD patients, as reflected by SDNN and HRR improvement. This benefit was associated with ANS baseline dysfunction, lower systemic inflammation, quit smoking and normal LV function to mild left ventricular systolic dysfunction.

Keywords Autonomic nervous system-cardiac rehabilitation-coronary artery disease; heart rate recovery-heart rate variability.

\section{INTRODUCTION}

Autonomic nervous system (ANS) dysfunction is associated with increased risk of morbidity and mortality in coronary artery disease (CAD), especially the risk of

Address for correspondence:

Pedro Rio, MD, Dept. of Cardiology, Hospital de Santa Marta, Centro Hospitalar de Lisboa Central.

Rua de Santa Marta, n 50, 1169-024, Lisbon, Portugal.

E-mail: pedrosantosrio@gmail.com

Received 12 October 2015; revision accepted for publication 1 February 2016. sudden cardiac death ${ }^{1,2}$. Previous data have shown an increase of sympathetic nervous activity and decrease of vagal tone after an acute coronary syndrome ${ }^{3,4}$. Autonomic function may be assessed by relatively easy, non-invasive and cost-effective methods as resting heart rate (HR), heart rate variability (HRV), which analyse variation in the intervals between consecutive normal heart beats in milliseconds, and heart rate recovery (HRR) in exercise testing, that can be defined as the reduction in the heart rate from the rate at peak exercise to the rate one minute after the cessation of exercise ${ }^{5,6}$. Exercisebased cardiac rehabilitation (CR) has been associated with positive effects on autonomic function in $\mathrm{CAD}$ patients ${ }^{7,8}$, with HRV and HRR increases. This improvement in autonomic balance seems to correlate with increased 
exercise capacity, although few studies identified the parameters associated with ANS function modification.

We aimed to evaluate the modulating effect of $C R$ on ANS function in CAD patients and to identify CAD risk factors and functional parameters associated with ANS function modification.

\section{METHODS}

CAD patients who completed a phase-2 CR programme and pre- and post-CR complementary evaluation in our centre between January 2004 and January 2013 were retrospectively evaluated. Patients with a pacemaker or atrial fibrillation and those who failed to attend at least $80 \%$ of the exercise sessions or did not complete all the complementary evaluation were excluded.

In ACS patients, pre-CR evaluation was performed in the first 2 weeks and the phase-2 CR programme was initiated between 2-4 weeks after discharge.

\section{CR programme}

The CR programme consisted of 12 weeks of exercise training and lifestyle modification. The exercise training programme was performed three days per week (36 sessions). Each exercise session included 10 minutes of warm-up, 30 minutes of aerobic exercise, 10 minutes of muscular strengthening and 5 minutes of cooling down and stretching. In the exercise prescription, the maximal exercise intensity was calculated as a percentage of the heart rate achieved at the anaerobic threshold in the treadmill exercise test. Individualized exercise prescription was periodically adjusted to encourage a gradual increase in overall exercise performance.

In addition to the supervised exercise sessions, each patient was encouraged to exercise daily outside the formal exercise programme. All patients received dietary counselling by a nutrition specialist and selected patients received psychological support with self-management behaviour and underwent smoking cessation consult.

\section{Complementary evaluation}

The complementary evaluation consisted of an immediate pre- and post-CR HRV study, cardiopulmonary exercise testing (CPT) and transthoracic echocardiography.

The HRV study was based on a 24-hour Holter recording by analysing the standard deviation of the $\mathrm{NN}$ (regular R-R) intervals (SDNN).

Before treadmill exercise testing, the resting haemodynamic parameters (HR, systolic and diastolic blood pressure) were measured. Resting HR was measured fifteen minutes before the onset of the stress test and after the patient had remained in a supine position for at least five minutes, in a quiet, mild-temperature environment. With the patient seated, basal blood pressure was obtained by the mean of two measurements with a 1-min interval, using a digital automatic blood pressure monitor. For systolic blood pressure, if there was more than $5 \mathrm{mmHg}$ difference between the two readings, a third reading was obtained for the mean determination. Pharmacologic therapy, namely beta blockers, was maintained during pre- and post-CR evaluation. Non-smoking was strictly recommended on the day of the test. Then, a symptom-limited treadmill exercise test was conducted according to the modified Bruce protocol. The HR was monitored during the test and averaged every 10 seconds, using 12-lead electrocardiogram readings. Peak HR was considered the highest value achieved during the test. Blood pressure was measured with a mercury sphygmomanometer during the last 45 seconds of each stage of exercise, and in the last 15 seconds of exercise, nearing the end of the test. Peak systolic and diastolic blood pressures were recorded as the highest value achieved during the test. HRR was determined by calculating the difference between $\mathrm{HR}$ at peak exercise and HR at one minute after completion of the exercise. HR reserve was defined as the difference between peak and resting HR. Patients were instructed to sit after ending the test, and there was no cool-down. Pulmonary gas exchange analysis was performed throughout the test, including the measurement of oxygen uptake $\left(\mathrm{VO}_{2}\right)$ (SensorMedics Vmax 229, Yorba Linda, Calif.). Peak $\mathrm{VO}_{2}\left(\mathrm{pVO}_{2}\right)$ was defined as the highest $\mathrm{VO}_{2}$ attained during the final 30 seconds of exercise. By transthoracic echocardiography, the left ventricular ejection fraction (LVEF) (Simpson's biplane method) and the E/A ratio were determined.

\section{Statistical analysis}

Discrete data are expressed as frequency (percentage) and continuous variables as mean $\pm \mathrm{SD}$, or as median (minimum-maximum), when appropriate. Pre- and post-CR data were compared using the Student's independent $t$-test. The association of clinical and demographic characteristics, natriuretic peptides levels, CPT and echocardiographic parameters with SDNN and HRR improvement were studied using the chi-square test or the Student's independent $t$-test and by backward multivariate logistic regression analysis, using significant variables. Data were analysed using the SPSS version 17.0 statistical software and the level of statistical significance was $\alpha=0.05$. 


\section{RESULTS}

Our sample included 142 patients (85.9\% male, $57.8 \pm 10.2$ years), $85 \%$ post-acute coronary syndromes of which 91 patients (64\%) were in the first month following ST-segment elevation myocardial infarction ( $76 \%$ had percutaneous coronary intervention complete revascularization), and $15 \%$ had stable CAD. The clinical characteristics of the sample are presented in table 1. All patients were on antiplatelet therapy, statin, and a stable dose of beta blockers.

Pre- and post-CR data are presented in table 2 . There were significant improvements in $\operatorname{SDNN}(\Delta 6.9 \pm 34.5 \mathrm{~ms}$; $120.7 \pm 40.7$ vs $127.6 \pm 41.5 \mathrm{~ms}, P=0.019)$, resting $\operatorname{HR}(\Delta$ $2.4 \pm 11.0 \mathrm{~min}^{-1} ; 71.3 \pm 10.7$ vs $69.0 \pm 10.9 \mathrm{~min}^{-1}$, $P=0.015)$, peak HR $\left(\Delta 2.8 \pm 14.7 \mathrm{~min}^{-1} ; 138.3 \pm 21.0\right.$ vs $\left.141.2 \pm 21.3 \mathrm{~min}^{-1}, P=0.027\right)$, HR reserve $(\Delta 3.3 \pm 15.6$ $\min ^{-1} ; 67.0 \pm 20.1$ vs $\left.72.2 \pm 20.0 \mathrm{~min}^{-1}, P<0.001\right)$, HRR $\left(\Delta 3.3 \pm 15.6 \mathrm{~min}^{-1} ; 23.8 \pm 12.3\right.$ vs $27.1 \pm 12.5 \mathrm{~min}^{-1}$, $P=0.017), \mathrm{pVO}_{2}\left(\Delta 1.8 \pm 6.0 \mathrm{~mL} . \mathrm{kg} . \mathrm{min}^{-1} ; 25.6 \pm 6.8\right.$ vs $27.5 \pm 7.2 \mathrm{~mL} . \mathrm{kg}$. $\left.\mathrm{min}^{-1}, P=0.001\right)$ and $\mathrm{E} / \mathrm{A}$ ratio $(\Delta-0.15 \pm 0.45 ; 1.20 \pm 0.54$ vs $1.06 \pm 0.39, P<0.001)$.

The baseline independent factors associated with SDNN improvement were ESR (OR 0.911; 95\% confidence intervals (CI) $0.838-0.989, P=0.027$ ), $\mathrm{LVEF}>40 \%$ (OR 7.879; 95\% CI 2.753-37.351, $P=0.009$ ) and SDNN $<100 \mathrm{~ms}$ (OR 9.325; 95\% CI 1.775-48.978, $P=0.008$ ) as presented in table 3 . The independent predictors of HRR improvement were baseline abnormal HRR (OR 8.023; 95\% CI 1.049-64.811, $P=0.035)$ and quit smoking (OR 4.323 ; $95 \%$ CI 1.136-16.454, $P=0.014$ ).

\section{DISCUSSION}

In this retrospective cohort we evaluated the modulating effect of CR on ANS function in CAD patients and identified the clinical and functional parameters associated with ANS function modification.

Autonomic function was assessed using three different techniques: resting HR, HRV and HRR, which have been previously validated ${ }^{5,6}$.

These parameters reflect the balance of sympathetic and parasympathetic effects, and their interactions. Each of these compounds had prognostic significance in primary and secondary prevention settings, even though a pathophysiological link has not been established. In the general population, the decrease of HRV and high resting HR can mean an increased risk of coronary heart disease, death and cardiac mortality ${ }^{7-9}$, whereas abnormal HRR increases the relative risk of death ${ }^{10}$.

In patients with cardiovascular disease, ANS dysfunction is associated with worse prognosis ${ }^{2}$ and might be a therapeutic target. Decreased HRV has been associated
Table 1 Clinical characteristics of the sample

\begin{tabular}{|c|c|}
\hline & $\begin{array}{c}\text { Total } \\
n=142\end{array}$ \\
\hline Age, mean (SD), (years) & $57.8(10.2)$ \\
\hline Male, $n(\%)$ & $122(85.9)$ \\
\hline Sedentary (no regular physical exercise), $\mathrm{n}(\%)$ & $98(69)$ \\
\hline Smoking, $n$ (\%) & $60(42)$ \\
\hline Dyslipidaemia, n (\%) & $86(61)$ \\
\hline Arterial hypertension, $n(\%)$ & $71(50)$ \\
\hline $\mathrm{BMI}$, mean (SD) $\left(\mathrm{Kg} / \mathrm{m}^{2}\right)$ & $27.7 \pm 3.8$ \\
\hline Obesity, n (\%) & $38(27)$ \\
\hline Diabetes mellitus, $\mathrm{n}(\%)$ & $23(16)$ \\
\hline Family history of cardiovascular disease, $n(\%)$ & $21(15)$ \\
\hline Prior Ml, n (\%) & $19(13)$ \\
\hline $\mathrm{SBP}$, mean $(\mathrm{SD})(\mathrm{mmHg})$ & $121 \pm 15$ \\
\hline $\mathrm{DBP}$, mean $(\mathrm{SD})(\mathrm{mmHg})$ & $72 \pm 10$ \\
\hline STEMI, n (\%) & $91(64)$ \\
\hline NSTEMI, n (\%) & $30(21)$ \\
\hline Stable CAD, $n(\%)$ & $21(15)$ \\
\hline Multivessel disease, $n(\%)$ & $58(41)$ \\
\hline NYHA function class $\geq 2, n(\%)$ & $42(30)$ \\
\hline Creatinine (mg/dL, mean (SD) & $0.93 \pm 0.23$ \\
\hline eGFR (mL/min per $\left.1.72 \mathrm{~m}^{2}\right)$, mean (SD) & $101 \pm 34$ \\
\hline hs-CRP (mg/dL), mean (SD) & $13.4 \pm 24.9$ \\
\hline Erythrocyte sedimentation rate $(\mathrm{mm} / \mathrm{h})$, mean (SD) & $13.5 \pm 17.9$ \\
\hline Fasting glycaemia, mean (SD) (mg/dL) & $110 \pm 26$ \\
\hline Total cholesterol, mean (SD) (mg/dL) & $153 \pm 35$ \\
\hline LDL-cholesterol, mean (SD) (mg/dL) & $96 \pm 29$ \\
\hline HDL-cholesterol, mean (SD) (mg/dL) & $39 \pm 11$ \\
\hline Triglycerides, mean (SD) (mg/dL) & $109 \pm 57$ \\
\hline LVEF, mean (SD) (\%) & $54.3 \pm 10.3$ \\
\hline LVEDD, mean $(\mathrm{SD})(\mathrm{mm})$ & $54.4 \pm 8.5$ \\
\hline LVESD, mean (SD) (mm) & $35.7 \pm 9.6$ \\
\hline IVST, mean (SD) (mm) & $10.3 \pm 2.3$ \\
\hline PWT, mean (SD) (mm) & $9.5 \pm 1.8$ \\
\hline LV mass, mean $(\mathrm{SD})\left(\mathrm{g} / \mathrm{m}^{2}\right)$ & $99.8 \pm 35$ \\
\hline
\end{tabular}

Values are mean \pm SD or N (\%). BMI: body mass index, Ml: myocardial infarction, SBP: systolic blood pressure, DBP: diastolic blood pressure, STEMI: ST-segment elevation myocardial infarction, NSTEMI: non-ST-segment elevation myocardial infarction, CAD, coronary artery disease, NYHA: New York Heart Association, eGFR: estimated glomerular filtration rate, hs-CRP: high-sensitivity C-reactive protein, LDL: low-density lipoprotein, HDL: high-density lipoprotein, LVEF: left ventricular ejection fraction, LVEDD: left ventricular end-diastolic diameter, LVESD: left ventricular end-systolic diameter, IVST: interventricular septal thickness, PWT: posterior wall thickness, LV mass: left ventricular mass.

with increased mortality and sudden death ${ }^{11}$. Likewise, HR correlates with mortality and cardiac events ${ }^{12}$. Also in this group, decreased HRR is an independent predictor of mortality ${ }^{13}$. 
Table 2 Pre-and post-cardiac rehabilitation data

\begin{tabular}{|c|c|c|c|}
\hline & Pre-CR & Post-CR & P-value \\
\hline Standard deviation of the NN intervals (ms) & $120.7 \pm 40.7$ & $127.6 \pm 41.5$ & 0.019 \\
\hline Resting heart rate $\left(\mathrm{min}^{-1}\right)$ & $71.3 \pm 10.7$ & $69.0 \pm 10.9$ & 0.015 \\
\hline Peak heart rate $\left(\mathrm{min}^{-1}\right)$ & $138.3 \pm 21.0$ & $141.2 \pm 21.3$ & 0.027 \\
\hline Basal systolic blood pressure $(\mathrm{mmHg})$ & $121.3 \pm 15.0$ & $119.6 \pm 14.8$ & 0.311 \\
\hline Basal diastolic blood pressure $(\mathrm{mmHg})$ & $71.5 \pm 9.9$ & $71.6 \pm 10.7$ & 0.866 \\
\hline Peak systolic blood pressure (mmHg) & $171.6 \pm 24.9$ & $170.6 \pm 22.6$ & 0.654 \\
\hline Peak diastolic blood pressure $(\mathrm{mmHg})$ & $82.3 \pm 11.6$ & $80.5 \pm 10.2$ & 0.160 \\
\hline Heart rate reserve $\left(\mathrm{min}^{-1}\right)$ & $67.0 \pm 20.1$ & $72.2 \pm 20.0$ & $<0.001$ \\
\hline Heart rate recovery $\left(\mathrm{min}^{-1}\right)$ & $23.8 \pm 12.3$ & $27.1 \pm 12.5$ & 0.017 \\
\hline Cardiopulmonary testing duration (min) & $13.5 \pm 3.2$ & $15.3 \pm 2.4$ & 0.140 \\
\hline Peak oxygen consumption (mL.kg.min ${ }^{-1}$ ) & $25.6 \pm 6.8$ & $27.5 \pm 7.2$ & 0.001 \\
\hline Left ventricular ejection fraction (\%) & $54.3 \pm 10.3$ & $54.9 \pm 10.4$ & 0.192 \\
\hline E/A ratio & $1.20 \pm 0.54$ & $1.06 \pm 0.39$ & $<0.001$ \\
\hline
\end{tabular}

Values are mean \pm SD.

Table 3 Factors associated with SDNN and HRR improvement

\begin{tabular}{|c|c|c|c|c|}
\hline \multirow[t]{2}{*}{ Variable } & \multicolumn{2}{|l|}{ Univariable analysis } & \multicolumn{2}{|l|}{ Multivariable analysis } \\
\hline & Odds ratio $(95 \%$ Cl) & P-value & Odds ratio $(95 \% \mathrm{Cl})$ & P-value \\
\hline \multicolumn{5}{|l|}{ SDNN improvement } \\
\hline Obesity & $2.444(1.077-5.544)$ & 0.033 & $1.623(0.402-6.543)$ & 0.496 \\
\hline ESR & $0.964(0.929-1.000)$ & 0.047 & $0.911(0.838-0.989)$ & 0.027 \\
\hline LVEF $>40 \%$ & $3.292(1.061-10.209)$ & 0.039 & $7.879(2.753-17.351)$ & 0.009 \\
\hline E/A ratio & $2.667(1.140-6.243)$ & 0.024 & $3.388(0.678-16.916)$ & 0.137 \\
\hline SDNN $<100 \mathrm{~ms}$ & $4.577(2.047-10.232)$ & $<0.001$ & $9.325(1.775-48.978)$ & 0.008 \\
\hline \multicolumn{5}{|l|}{ HRR improvement } \\
\hline Quit smoking & $3.857(1.236-12.040)$ & 0.020 & $4.323(1.136-16.454)$ & 0.014 \\
\hline Abnormal HRR & $18.655(2.412-144.276)$ & 0.005 & $8.023(1.049-64.811)$ & 0.035 \\
\hline LVEF $<35 \%$ & $0.092(0.011-0.772)$ & 0.028 & $0.115(0.008-1.642)$ & 0.111 \\
\hline
\end{tabular}

SDNN: standard deviation of the NN (regular R-R) intervals, ESR: erythrocyte sedimentation rate, LVEF: left ventricular ejection fraction, HHR: heart rate recovery.

Another advantage of the autonomic nervous system evaluation through these three parameters is that they are easy to use and inexpensive. It may be a powerful and convenient tool for risk stratification and for monitoring the improvement after exercise training in patients with coronary artery disease.

We must point out that rest HR and HR response was influenced by therapy, however, patients have been evaluated pre- and post-CR with the same therapy, including beta blockers.

The CR programme was associated with a significant improvement in ANS function as assessed by the three parameters. In this study we observed a significant improvement of the resting $\operatorname{HR}\left(\triangle 2.4 \pm 11.0 \mathrm{~min}^{-1}\right.$; $71.3 \pm 10.7$ vs $\left.69.0 \pm 10.9 \mathrm{~min}^{-1}, P=0.015\right)$ and $\mathrm{HRR}$ ( $\Delta 3.3 \pm 15.6 \mathrm{~min}^{-1} ; 23.8 \pm 12.3$ vs $27.1 \pm 12.5 \mathrm{~min}^{-1}$,
$P=0.017)$. Other studies previously demonstrated similar benefits after exercise training ${ }^{14,15}$. Ribeiro et al. ${ }^{15}$ in a welldesigned prospective, randomized, controlled trial, found an improvement of resting HR by $5.5 \mathrm{~min}^{-1}$ and an increase of HRR by $4 \mathrm{~min}^{-1}$, in the training group, after 8 weeks of aerobic exercise, whereas the control group remained unchanged.

After exercise, the interval of HRR predominantly results from parasympathetic reactivation with sympathetic and non-autonomic components playing minor roles. Exercise-based cardiac rehabilitation has been shown to reduce total mortality, cardiac mortality, hospital admissions ${ }^{16}$ and sudden death ${ }^{17}$. Therefore, one acceptable reason for the improvement of these outcomes is the autonomic function modification, mainly reflecting the antiarrhythmic characteristic of the 
parasympathetic nervous system ${ }^{18}$. Other improvements of ANS, after exercise training, sharing similar pathophysiological mechanisms, are the increased resting arterial baroreflex sensitivity, the decrease in muscle sympathetic nerve activity, and the reduced circulating catecholamines and angiotensin II levels ${ }^{19}$.

It is difficult to know if there is a clinical advantage in continuously improving the HRR or resting HR. Jouven et al. ${ }^{9}$ reported, in a cohort of asymptomatic working men, that a HRR $<25 \mathrm{bpm}$ after the first minute of recovery provides a relative risk of 2.2 of sudden cardiac death compared with the highest-percentile HRR group ( $>40 \mathrm{bpm}$ ). A RHR $>75 \mathrm{bpm}$ conferred a relative risk for sudden death of 3.9 compared with the lowest-percentile resting HR group $(<60 \mathrm{bpm})$. There seems to be a continuous relationship between prognostic and resting HR, with no observed threshold ${ }^{10}$. In this study, patients with decreased HRR achieved greater improvements in this parameter $(<12 \mathrm{bpm}, \mathrm{n}=20-\Delta 19.1 \pm 14.1 \mathrm{~ms} ;<25 \mathrm{bpm}$, $\mathrm{n}=72-\Delta 9.8 \pm 14.8 \mathrm{~ms}, P<0.001)$.

Another non-invasive parameter of ANS is HRV, which is the oscillation in the intervals between consecutive heartbeats. Commonly used time domain measures of HRV include standard deviation of normal R-R intervals (SDNN) which are also thought to be a marker of parasympathetic cardiac modulation. It is accepted that some therapies may improve outcomes by an increase of HRV. This is true for patients with heart failure who are subject to cardiac resynchronization therapy ${ }^{20}$ and to exercise training ${ }^{21}$. Significant improvements in HRV in myocardial infarction patients with exercise were reported in some controlled trials ${ }^{22}$.

In the present study there was a significant improvement of the SDNN after CR $(\Delta 6.9 \pm 34.5 \mathrm{~ms}$; $120.7 \pm 40.7 \mathrm{~ms}$ vs $127.6 \pm 41.5 \mathrm{~ms}, P=0.019)$, and patients with lower SDNN $(<100 \mathrm{~ms}, \mathrm{n}=51)$ had greater improvement $(\Delta 31.2 \pm 50.0 \%$ vs $-0.6 \pm 20.7 \%, P<0.001)$. It is difficult to define a cut-off value of SDNN that defines impaired HRV and a threshold for no more improvement in outcomes. In this cohort high baseline HRV values correlate with less increase in SDNN and plateau has been previously described ${ }^{23}$.

Few studies have previously identified the characteristics associated with ANS function modification. In our cohort, lower erythrocyte sedimentation rate, normal or mild systolic dysfunction and tobacco cessation were independent predictors of improved ANS.

In the literature an association is described between inflammation and autonomic dysfunction in CAD patients $s^{24,25}$ and this combination seems to have a synergistic effect ${ }^{26}$. The "inflammatory reflex" proposed by Tracey ${ }^{27}$ suggests that the activation of the vagal nerve leads to reduced production of inflammatory cytokines, thus the increase in vagal activation induced by exercise training could be an important mechanism to improve the inflammatory status ${ }^{28}$. Whelton et al. ${ }^{29}$ found that an elevated resting heart rate is independently associated with elevated inflammatory biomarkers, such as highsensitivity C-reactive protein, even after adjustment for physical activity levels. Our results, of better improvement of SDNN in patients with CAD and with lower erythrocyte sedimentation rate, could reflect this finding as autonomic imbalance contributes to or is affected by increased inflammation.

In the same manner, heart failure is associated with more severe ANS dysfunction ${ }^{30}$, with sympathetic and renin-angiotensin-aldosterone hyperactivity. This could prevent greater improvements in HRV compared to patients with a normal systolic function. This result should not keep us from pushing because there is evidence that the reduction of sympathetic activity by exercise training in heart failure patients is associated with a better clinical outcome $e^{31,32}$.

Tobacco use is associated with autonomic imbalanceand decreased HRV ${ }^{33,34}$ mainly due to nicotine exposure with catecholamine release and augmented sympathetic outflow $^{35}$. In this sense, smoking cessation leads to an increase of $\mathrm{HRV}^{36}$. In our cohort of patients, smoking cessation was an independent predictor of HRR improvement. The mechanism behind this fact is the same for $\mathrm{HRV}$, since rapid decline in HR following exercise is largely due to parasympathetic restoration and both, exercise and smoking cessation in chronic smokers, increase vagal tone.

Medication may alter ANS function, particularly beta blockers, with clinical benefits ${ }^{37}$. As we mentioned before, all the patients were on beta blockers, with a stable dose during $\mathrm{CR}$, thus the positive effects on ANS must have come from exercise training ${ }^{38}$.

The main finding of this work was that CR programme generated a positive effect on ANS, mainly in those with autonomic dysfunction. CAD patients, in sinus rhythm, with lower systemic inflammation and with normal or mild systolic dysfunction were more likely to improve ANS function.

\section{LIMITATIONS}

This was a retrospective analysis of consecutively admitted CAD patients in sinus rhythm and the results reflect a single-centre experience without control group.

Smoking status was assessed by self-reporting rather than a biochemical method, in the group of smokers, the burden of tobacco use was not assessed. This fact could have clinical relevance because heavier smokers have greater autonomic dysfunction and isolated nicotine use deleteriously affects $\mathrm{HRV}^{39}$. 


\section{CONCLUSION}

Cardiac rehabilitation induced a positive modulation of the autonomic nervous system function in coronary artery disease patients. This benefit was more pronounced in patients with autonomic nervous system dysfunction, objectively demonstrated by SDNN inferior to $100 \mathrm{~ms}$ and abnormal heart rate recovery, and also with normal LV function to mild left ventricular systolic dysfunction and with lower erythrocyte sedimentation rate.

\section{CONFLICT OF INTEREST: none.}

\section{REFERENCES}

1. De Ferrari GM, Sanzo A, Bertoletti A, Specchia G, Vanoli E, Schwartz PJ. Baroreflex sensitivity predicts long-term cardiovascular mortality after myocardial infarction even in patients with preserved left ventricular function.

J Am Coll Cardiol 2007; 50: 2285-90.

2. Palatini $P$, Julius $S$. The role of cardiac autonomic function in hypertension and cardiovascular disease.

Curr Hypertens Rep 2009; 11: 199-205.

3. Graham LN, Smith PA, Stoker JB, Mackintosh AF, Mary DA. Time course of sympathetic neural hyperactivity after uncomplicated acute myocardial infarction. Circulation 2002; 106: 793-7.

4. Osculati G, Grassi G, Giannattasio C, Seravalle G, Valagussa F, Zanchetti A, Mancia G. Early alterations of the baroreceptor control of heart rate in patients with acute myocardial infarction. Circulation 1990; 81: 939-48.

5. Cole CR, Blackstone EH, Pashkow FJ, Snader CE, Lauer MS. Heart-rate recovery immediately after exercise as a predictor of mortality. NEngl J Med 1999; 341: 1351-7.

6. La Rovere MT, Bigger JT Jr, Marcus FI, Mortara A, Schwartz PJ. Baroreflex sensitivity and heart-rate variability in prediction of total cardiac mortality after myocardial infarction. ATRAMI (Autonomic Tone and Reflexes After Myocardial Infarction) Investigators. Lancet 1998; 351: 478-84.

7. Kannel W, Kannel C, Paffenbarger R, Cupples P, Cupples L. Heart rate and cardiovascular mortality: the Framingham Study. Am Heart J 1987; 113: 1489-94.

8. Tsuji H, Larson MG, Venditti FJ Jr, Manders ES, Evans JC, Feldman CL, Levy D. Impact of reduced heart rate variability on risk for cardiac events. The Framingham Heart Study. Circulation 1996; 94: 2850-5.

9. Jouven X, Empana J, Schwartz P, Desnos M, Courbon $D$, Ducimetière $P$. Heart-rate profile during exercise as a predictor of sudden death. NEngl J Med 2005; 352: 1951-8.

10. Cole C, Foody J, Blackstone E, Lauer M. Heart rate recovery after submaximal exercise testing as a predictor of mortality in a cardiovascularly healthy cohort. Ann Intern Med 2000; 132: 552-5.

11. Lanza G, Guido V, Galeazzi M, Mustilli M, Natali R, lerardi C, Milici C, Burzotta F, Pasceri V, Tomassini F, Lupi A, Maseri A. Prognostic role of heart rate variability in patients with recent acute myocardial infarction.

Am J Cardiol 1998; 82: 1323-8.
12. Diaz A, Bourassa MG, Guertin MC, Tardif JC. Long-term prognostic value of resting heart rate in patients with suspected or proven coronary artery disease. Eur Heart J 2005; 26: 967-74.

13. Vivekananthan $D$, Blackstone $E$, Pothier $C$, Lauer $\mathrm{M}$. Heart rate recovery after exercise is a predictor of mortality, independent of the angiographic severity of coronary disease. J Am Coll Cardio/ 2003; 42: 831-8.

14. Giallauria F, De Lorenzo A, Pilerci F, Manakos A, Lucci R, Psaroudaki M, D'Agostino M, Del Forno D, Vigorito C. Long-term effects of cardiac rehabilitation on end-exercise heart rate recovery after myocardial infarction.

Eur J Cardiovasc

Prev Rehabil 2006; 13: 544-50.

15. Ribeiro F, Alves AJ, Teixeira M, Mirandad F, Azevedo C, Duartea JA, Oliveira J. Exercise training enhances autonomic function after acute myocardial infarction: $\mathrm{A}$ randomized controlled study. Rev Port Cardiol 2012; 31: 135-41.

16. Heran BS, Chen JM, Ebrahim S, Moxham T, Oldridge N, Rees K, Thompson DR, Taylor RS. Exercise-based cardiac rehabilitation for coronary heart disease. Cochrane Database Syst Rev 2011; 7 CD001800.

17. O'Connor GT, Buring JE, Yusuf $S$, Goldhaber SZ, Olmstead EM, Paffenbarger RS $\mathrm{Jr}$, Hennekens $\mathrm{CH}$. An overview of randomized trials of rehabilitation with exercise after myocardial infarction. Circulation 1989; 80: 234-44.

18. Billman GE. Cardiac autonomic neural remodeling and susceptibility to sudden cardiac death: effect of endurance exercise training. Am J Physiol Heart Circ Physiol 2009; 297: H1171-93.

19. Mimura J, Yuasa F, Yuyama R, Kawamura A Iwasaki M, Sugiura T, Iwasaka T. The effect of residential exercise training on baroreflex control of heart rate and sympathetic nerve activity in patients with acute myocardial infarction. Chest 2005; 127: 1108-15.

20. Adamson P, Kleckner K, Van Hout W, Srinivasam S, Abraham W. Cardiac resynchronization therapy improves heart rate variability in patients with symptomatic heart failure. Circulation 2003; 108: 266-9.

21. Larsen Al, Gjesdal K, Hall C, Aukrust P, Aarsland T, Dickstein $\mathrm{K}$. Effect of exercise training in patients with heart failure: a pilot study on autonomic balance assessed by heart rate variability. Eur J Cardiovasc Prev Rehabil 2004; 11: $162-7$.
22. Lellamo $F$, Legramante $J M$, Massaro $M$, Raimondi G, Galante A. Effects of a resi- dential exercise training on baroreflex sensitivity and heart rate variability in patients with coronary artery disease: a randomized, controlled study. Circulation 2000; 102: 2588-92.

23. Goldberger JJ, Challapalli S, Tung R, Parker MA, Kadish AH. Relationship of heart rate variability to parasympathetic effect. Circulation 2001; 103: 1977-83.

24. Hamaad A, Sosin M, Blann AD, Patel J, Lip GYH, MacFadyen RG. Markers of inflammation in acute coronary syndromes: association with increased heart rate and reductions in heart rate variability. Clin Cardiol 2005; 28, 570-6.

25. von Känel R, Carney RM, Zhao S, Whooley MA. Heart rate variability and biomarkers of systemic inflammation in patients with stable coronary heart disease: findings from the Heart and Soul Study. Clin Res Cardiol 2011; 100: 241-7.

26. Sloan RP, McCreath H, Tracey KJ, Sidney S, Liu K, Seeman T. RR interval variability is inversely related to inflammatory markers: the CARDIA study. Mol Med 2007; 13:178-84.

27. Tracey KJ. The inflammatory reflex. Nature 2002; 420(6917): 853-9.

28. Milani RV, Lavie CJ, Mehra MR. Reduction in $C$-reactive protein through cardiac rehabilitation and exercise training. J Am Coll Cardiol 2004; 43: 1056-61.

29. Whelton SP, Narla V, Blaha MJ, Nasir K, Blumenthal RS, Jenny NS, Al-Mallah MH, Michos ED. Association between resting heart rate and inflammatory biomarkers (high-sensitivity C-reactive protein, interleukin-6, and fibrinogen) (from the Multi-Ethnic Study of Atherosclerosis). Am J Cardiol 2014; 113: 644-9.

30. Eisenhofer G, Friberg P, Rundqvist B, Quyyumi AA, Lambert G, Kaye DM, Kopin IJ, Goldstein DS, Esler MD. Cardiac sympathetic nerve function in congestive heart failure. Circulation 1996; 93: 1667-76.

31. Roveda F, Middlekauff HR, Rondon MU, Reis SF, Souza M, Nastari L, Barretto AC, Krieger EM, Negrão CE. The effects of exercise training on sympathetic neural activation in advanced heart failure: a randomized controlled trial. J Am Coll Cardiol 2003; 42: 854-60.

32. Fraga R, Franco FG, Roveda F, de Matos LN, Braga AM, Rondon MU, Rotta DR, Brum PC, Barretto AC, Middlekauff HR, Negrão CE. Exercise training reduces sympathetic nerve activity in heart failure patients treated with carvedilol. Eur J Heart Fail 2007; 9: 630-6. 
33. Eryonucu B, Bilge M, Guler N, Uzun K, Gencer M. Effects of cigarette smoking on the circadian rhythm of heart rate variability. Acta Cardiol 2000; 55: 301-5.

34. Morshedi-Meibodi A, Larson MG, Levy D, O'Donnell CJ, Vasan RS. Heart rate recovery after treadmill exercise testing and risk of cardiovascular disease events (The Framingham Heart Study).

Am J Cardiol 2002; 90: 848-52.

35. Narkiewicz K, van de Borne PJH, Hausberg $M$ Cooley PL, Winniford MD, Davison DE,
Somers VK. Cigarette smoking increases sympathetic outflow in humans. Circulation 1998; 98: 528-34.

36. Shinozaki N, Yuasa T, Takata S. Cigarette smoking augments sympathetic nerve activity in patients with coronary heart disease. Int Heart J 2008; 49: 261-72.

37. Lin JL, Chan HL, Du CC, Lin IN, Lai CW, Lin KT, Wu CP, Tseng YZ, Lien WP. Long-term beta-blocker therapy improves autonomic nervous regulation in advanced congestive heart failure: a longitudinal heart rate variability study.

Am Heart J 1999; 137: 658-65.

38. Malfatto $G$, Facchini M, Sala L, Branzi G, Bragato R, Leonetti G. Effects of cardiac rehabilitation and beta-blocker therapy on heart rate variability after first acute myocardial infarction.

Am J Cardiol 1998; 81: 834-40.

39. Harte $C B$, Meston CM. Effects of smoking cessation on heart rate variability among long-term male smokers. Int J Behav Med 2014; 21: 302-9. 
Copyright of Acta Cardiologica is the property of Acta Cardiologica and its content may not be copied or emailed to multiple sites or posted to a listserv without the copyright holder's express written permission. However, users may print, download, or email articles for individual use. 